See discussions, stats, and author profiles for this publication at: https://www.researchgate.net/publication/326775949

\title{
Household Coping Strategies after an Adult Non-Communicable Disease Death in Bangladesh
}

Preprint · August 2018

DOI: $10.13140 / R G .2 .2 .14213 .86245$

\section{CITATIONS}

6 authors, including:

Louis Niessen

Liverpool School of Tropical Medicine

242 PUBLICATIONS 4,831 CITATIONS

SEE PROFILE

Jahangir A. M. Khan

Liverpool School of Tropical Medicine

72 PUBLICATIONS 321 CITATIONS

SEE PROFILE
READS

71

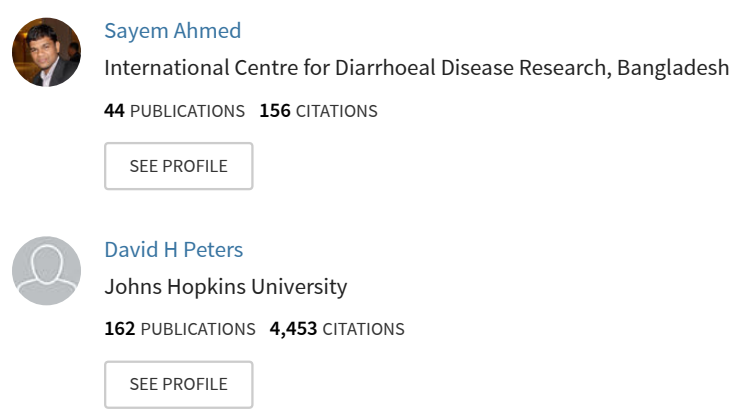

Some of the authors of this publication are also working on these related projects:

Project Integrated stroke services View project

Project Effectiveness and efficiency of quality-Improvement collaboratives View project 
Title: Household Coping Strategies after an Adult Non-Communicable Disease Death in Bangladesh

Short title: Coping after Non-Communicable Disease in Bangladesh

Authors: Andrew J. Mirelman ${ }^{1}$, Antonio J. Trujillo², Louis W. Niessen ${ }^{3}$, Sayem Ahmed ${ }^{4}$, Jahangir A. M. Khan ${ }^{3,4}$, David H. Peters ${ }^{2}$.

Institutions: ${ }^{1}$ Centre for Health Economics, University of York, United Kingdom. ${ }^{2}$ Department of International Health, Johns Hopkins Bloomberg School of Public Health, USA. ${ }^{3}$ Department of Clinical Sciences, Liverpool School of Tropical Medicine, United Kingdom. ${ }^{4} \mathrm{Health}$ Systems and Population Studies Division, icddr,b, Bangladesh.

Corresponding Author: Andrew J. Mirelman. Address: Centre for Health Economics - University of York, Alcuin 'A' Block, York, United Kingdom, YO10 5DD. Phone: +44-7508021569. Email: andrew.mirelman@york.ac.uk

Acknowledgments: None

Funding Source: This work was supported by the National Heart Lung Blood Institute (NHLBI) 


\section{Abstract}

When facing adverse health from non-communicable disease (NCD), households adopt coping strategies that may further enforce poverty traps. This study looks at coping after an adult NCD death in rural Bangladesh. Compared to similar households without NCD deaths, households with NCD deaths were more likely to reduce basic expenditure and to have decreased social safety net transfers. Household composition changes showed that there was demographic coping for prime age deaths through the addition of more women. The evidence for coping responses from NCDs in low- and middle-income countries may inform policy options such as social protection to address health-related impoverishment.

Keywords: Non-communicable disease, Coping, Bangladesh, Low-Income Country 


\section{Introduction}

Many low and middle-income countries are now facing an "epidemiologic transition" where noncommunicable diseases $(\mathrm{NCD})$ are becoming more prevalent and may have important economic consequences ${ }^{1}$. This is also seen in the low-income country of Bangladesh where research has shown a large increase in the burden from NCDs that is more concentrated in the poor and may even lead to impoverishment ${ }^{2-5}$. However, it is not as clear what mechanisms explain the potential impacts. This manuscript explores which coping strategies households employ after an adult NCD death and whether these are more likely to be used by households with such deaths versus those with no deaths.

Coping mechanisms, which are responses to adverse health events, may impose both direct and indirect costs and have important implications for poverty ${ }^{6-9}$. In the long term, households may become more vulnerable to future shocks and impoverishment ${ }^{10-12}$. For this reason, further understanding which coping strategies households use is important in low and middle-income country contexts ${ }^{13-16}$.

Previous studies in Bangladesh have found that households use several coping strategies when faced with poor health that may be detrimental to their welfare ${ }^{14,17,18}$. Coping is used to adjust for the economic impacts of illness such as high medical expenditures and has the potential to contribute to long term poverty. However, coping can also be associated with the economic impact of illness even if medical expenditures are low or zero. In this paper, we look at evidence of coping in a rural sub-district of Bangladesh. We utilize high-quality demographic surveillance data to look at the health impacts from non-communicable diseases over time. The results have implications for understanding the economic impacts of NCD as a growing health and economic threat in low- and middle-income countries. 


\subsection{Coping Strategies in Response to III Health}

Coping strategies can be classified into three broad categories: economic coping, demographic coping and behavioural coping ${ }^{18-20}$. Economic coping, includes strategies to directly adjust household consumption or resources. Examples include reducing expenditures on food and other basic items ${ }^{21}$. Reduced basic expenditure can have longer-term impacts on the well-being of children. Other examples of economic coping include selling productive asset or spending savings, which may increase vulnerability to future shocks ${ }^{22}{ }^{23}$.

Another form of economic coping is taking loans from microfinance institutions (MFI) ${ }^{18,24,25}$. There has been mixed evidence about the effectiveness of microfinance for mitigating the risk from shocks, but some evidence shows that it may help smooth the impacts of shocks ${ }^{26,27}$. In rural areas in low and middle-income countries there is still a high level of reliance on informal borrowing from sources such as friends, relatives and moneylenders ${ }^{19}$. Borrowing, from either formal or informal sources, may be detrimental to households when loans come with high interest rates $^{22}$. Finally, while not an active form of coping, declines in social safety net transfers pose larger constraints on household budgets.

Demographic coping takes place when there are household compositional changes. Deaths impose a change in the household composition which may require adjustment of household size and labour arrangements. Households can adjust size by either recruiting new members into the household or by sending members away ${ }^{28}$. The reduced labour supply that a household faces after a death is most detrimental when the death is to a prime-age member ${ }^{18}$. One study in Tanzania found that households do not replace human capital very well after deaths, with only $20 \%$ of households able to do $\mathrm{so}^{23}$.

A third category of coping relates to household behaviours that have an indirect effect on the household economic condition. Strategies here may be related to marriage and education. Early 
marriage may be one way to cope as this would mean one less person in the household and linkages to other family networks. Early marriage could have a harmful impact in terms of reduced education and labour force participation for a young bride, and is clearly linked to demographic coping as well ${ }^{29}$. For education, households with deaths to prime age members may be more likely to have a school-aged child leave education early and begin working ${ }^{21}$. Given the strong relationship between education and later life health and wealth, reduced levels of education may have harmful long-term consequences.

The decision to use a particular coping strategy may be related to characteristics of the household. Poor households may be more likely to use harmful coping strategies because safer ways of adjusting to the cost of the shock are not available to them ${ }^{30}$. Previous work looking at household coping from mortality shocks finds that rich households have more access to resources and social capital and can use private transfers. The poor may rely more on credit and be less likely to replace human capital $^{20,23,31}$.

The use of coping strategies will also depend on the characteristics of the deceased, depending on whether the deceased was of prime, working age or whether they were male or female $e^{23}$. Another determining factor may be the severity and duration of morbidity prior to the death, indicating whether households spend much time and resources on the ill person prior to the death.

\section{Data}

The data for this study come from the routine surveillance system from Matlab, Bangladesh administered through the International Center for Diarrhoeal Disease Research in Bangladesh (icddr,b). This ongoing demographic surveillance system has been administered for over fifty years ${ }^{32}$. In addition to the routine surveillance data, information is used from a survey designed to assess the economic impacts from adult NCD deaths. The survey included modules for demographic information for the household and the household head, information about the NCD 
death and deceased individual and a module to assess the coping strategies reported after the death. The survey was administered in 2012 for the group of households experiencing an adult NCD death in 2010 in Matlab. A similar survey for a comparison group of households with no death in 2010 were directly matched in a 2:1 ratio to deceased individuals based on characteristics of age, sex and village. Households with deaths from non-NCD causes were not included in the survey. Since comparison households did not have a reference point (i.e. date of death) for assessing impacts, they were instructed to make assessments based on seasonal milestones in comparable periods. The performance of the matching is reported in a later when assessing the balance between the groups. The quality of the data, owing to the availability of long-term census information in a rural low- and middle-income country setting, ensured that we were able to conduct accurate matching. Information for the household's demographics and socio-economic status prior to death was available from the surveillance system for the year 2009 and was linked by unique household identifiers with our survey.

\subsection{Dependent Measures of Household Coping}

Ten coping strategies were identified and classified into three categories ${ }^{18-20}$. These were:

A. Economic Coping

1. Decline in expenditure on basic items.

2. Taking out a high interest institutional loan.

3. Taking out a high interest independent loan.

4. Selling household assets.

5. Spending household savings.

6. Experiencing decreased transfers from social safety net programs.

B. Demographic Coping

7. Having someone move out of the household. 
8. Having someone move in to the household.

\section{Behavioral Coping}

9. Having someone in the household marry early.

10. Having someone in the household leave education.

The decline in basic expenditure was defined as a reduction in spending on items such as food and utilities in the period between the death, or comparable period, and the interview.

Detailed information was collected for the loan history of each household and two types of loans were specified, institutional loans received from banks or non-profit organizations and independent loans taken from friends, neighbours, relatives or moneylenders. Information on up to two loans per household of each type was collected. High interest loans are distinguished by whether the interest rate was higher than the standard commercial loan interest rate of $13 \%{ }^{25}$.

Further economic coping strategies included selling assets, spending savings and having a decrease in the amount of transfers received form social safety net programs. These variables all represented a decrease in the stock of financial resources or income streams that are available to households.

Two strategies of demographic coping were included - having a member move out of the household or having a member move in to the household. These were asked independently, thus a household was able to report having used both strategies. A second analysis of demographic coping was also conducted using the roster of household composition in the base year 2009 and two years after the death, in 2012. Dependent variables for this analysis included the total adult members aged 15 and above and the total number of children. For adults, these variables were also analysed separately by sex and prime age status. 
For the behavioural coping category, two strategies were included: whether a household had someone marrying early because of the NCD death or whether someone had to leave education to work or attend to the household because of the NCD death.

\subsection{Independent Variables}

NCD deaths were identified as all deaths in adults over 15 years of age that were classified as non-communicable disease based on the International Classification of Disease version 10 (ICD10) code in the Matlab demographic surveillance system. All non-communicable disease categories were included except for intentional and unintentional injuries. Explanatory variables at the household level that were included were: household size; age, sex and years of completed education of the head of the household; and a baseline indication of being poor based on being in the lower $40 \%$ of a self-rated five step ladder of economic condition.

Explanatory variables for the deceased individual included: the severity of ill health prior to death, prime age status, sex and position in the household. Illness severity was assessed with a timeline where households were asked about the length of severe and non-severe illness. Severe illness was defined as not being able to: work, go to school, or perform daily activities without assistance. In the regression analysis a dummy variable was used for whether the time of illness was above or below the median period of severe morbidity for the sample.

\subsection{Summary Statistics}

Descriptive information for the study population is provided Table 1. The households in each of the groups appear balanced in all of the characteristics. $44 \%$ of the NCD households and $43 \%$ of the comparison households rated themselves as poor, giving some validation of the matching process. This is higher than the rural poverty rate as measured according to a consumption line by the World Bank in 2010 which was $35.16 \%{ }^{33}$. 
[Insert Table 1 here]

For individual characteristics, the population appears to be evenly balanced except for the variable indicating whether the individual was the head or spouse of the head of the household. For this variable, the comparison group is comprised of $7 \%$ more household heads and their spouses than the NCD group. The length of severe illness leading up to an NCD death was around a third of a year.

Table 2 lists the results for the total coping strategies and categories used between groups. These were relatively stable for both groups. The NCD death households were more likely to use zero or one strategy, and the comparison households were more likely to use two or more. A similar pattern was seen for use of coping by category, where comparison households seem slightly more likely to use multiple coping categories. To understand the determinants of coping among NCD households and whether NCD leads to coping, regression analyses are conducted.

[Insert Table 2 here]

\section{Empirical Methodology}

\subsection{Regression within NCD Sample}

A multivariate logistic regression model was specified for each coping strategy to examine which characteristics were associated with their use. Multinomial logistic regression was determined to not be suitable since the outcomes were not mutually exclusive. A model was first run with only the NCD households to evaluate the determinants of using each coping strategy conditional on having a death in the household. This model was specified as follows for each coping strategy:

$\operatorname{logit}\left(Y_{h}\right)=\beta_{0}+\beta_{1} X_{1}+\cdots+\beta_{n} X_{n}$

In equation (1), $\operatorname{logit}\left(Y_{h}\right)$, is the log odds that a household $h$ adopts the coping strategy. $\beta_{0}$ is the intercept term, and the vector $X^{\prime}$ represents $n$ number of independent variables at the individual 
and household level such as severity of illness as well as exogenous controls (see Table 1). The vector of coefficients, $\beta_{1 \ldots n}^{\prime}$ represents the change in the explanatory variable that relates to the use of each coping strategy. All standard errors are clustered at the village level.

\subsection{Regression Model for Decision to Cope}

To understand the impact of the NCD on coping in the population, we next look at coping in relation to a matched comparison group of households. This is equivalent to a discrete choice model of coping adoption since households attempt to smooth the effects of adverse health by using coping strategies that provide the highest utility constrained by their ability to use them ${ }^{34}$. This model is again a multivariate logistic regression for each coping strategy with the choice to use a coping strategy $\left(Y_{h}=1\right)$ or to not use it $\left(Y_{h}=0\right)$ as the dependent variable for each household $h^{35}$.

$\operatorname{logit}\left(Y_{h}\right)=\beta_{0}+\delta N C D+\beta_{1} X_{1}+\cdots+\beta_{n} X_{n}$

Equation 2 uses a vector of $X^{\prime}{ }_{1 \ldots n}$ for individual and household level controls and clusters standard errors at the village level. The dummy variable, $N C D$, indicates whether a household experienced an NCD death and the coefficient $\delta$ represents the association with the use of a particular coping strategy after an NCD death.

To understand how the odds of using a coping strategy may differ by the characteristics of the death itself, the model in equation 2 is also estimated using dummies to separate the NCD variable into whether it was to a prime age person, to a head of household, to a male or a female, or for a death with long period of prior severe morbidity. All four of the equations included the vector of exogenous controls and clustered the standard errors according at the village level. 


\subsection{Difference-in-Difference Analysis}

For a limited set of variables, we were further able to extend the discrete choice set-up to account for the intensity of demographic coping. This utilised data from the household rosters in a difference-in-difference (DiD) analysis combined with direct matching. The outcomes were the differences in the number of adults and children present in the household after death relative to the differences in the comparison group. The direct matching ensures that potential confounders of household status are balanced at baseline and the DiD approach accounts for time-variant observable and time-invariant unobservable factors of the households by taking into account differences in the outcome variable both within and between each group ${ }^{23}$.

For this DiD, first, the mean difference in the outcomes of household composition for each group between the baseline year and two years post death is estimated (first difference). Then these differences are compared to each other (second difference) with the following equation:

$E(\delta)=E\left(\Delta Y_{N C D}\right)-E\left(\Delta Y_{\text {Comp }}\right)$

In equation 3, the term $E(\Delta Y)$ is the change in the expected value of the composition variable for each of the NCD and comparison groups. The $E(\delta)$ term denotes the DiD estimate of the change in the expected value of the composition variable of interest.

To assess the significance of the DiD estimate in equation 3, an ordinary least squares (OLS) regression model is specified:

$Y_{h t}=\beta_{0}+\beta_{1} N C D+\beta_{2}$ Time $+\beta_{3} N C D *$ TIME $+\varepsilon_{t}$

In equation $4, Y_{h t}$ is the composition variable of interest for household $h$ at time $t . \beta_{0}$ is the intercept, $\beta_{1}$ and $\beta_{2}$ are the main effects of the change in composition explained by a dummy variable representing whether a household had an NCD death (NCD) and the time period (TIME). 
The coefficient for the interaction between having an NCD death and time, $\beta_{3}$, represents the DiD estimate provided in equation 3, but now includes a standard deviation clustered at the village level and allows one to assess statistical significance.

To further test the robustness of the $\mathrm{DiD}$ estimates, equation 4 is run with a vector of exogenous household controls much like the previous logistic regressions.

\section{Results}

\subsection{Determinants of Coping within NCD Sample}

Multivariate results for the ten coping strategies in the households with an NCD death show that several important determinants of coping are whether there is a prime age death, male death, severe illness or the household is poor (Table 3). Specifically, a death with a long period of prior severe morbidity leads to a higher likelihood of a household reducing expenditure on basic items (coefficient 0.359 , s.e. 0.143 ). For taking out high-interest loans, being poor leads to a higher likelihood of taking out institutional loans (coefficient 0.808 , s.e. 0.321 ). A household with a prime age death was more likely to sell assets (coefficient 1.004 , s.e. 0.417 ). There were no significant associations seen for determinants of demographic coping, however for behavioural coping, households with prime age deaths were more likely to both have someone marry early and to have someone leave education (marry early coefficient 1.243, s.e. 0.540; leave education coefficient 0.830 , s.e.0.417). In addition, female deaths were strongly associated with having a household member marry early (coefficient 1.387 , s.e. 0.633 ).

[Insert Table 3 here]

Overall, the coefficient on the variable for a prime age death is significant for the most number of coping strategies, three out of ten. Having a male death, a long period of severe morbidity, and 
being poor were each significantly associated with the use of one coping strategy in either the economic or behavioural categories.

\subsection{Decision to Cope after NCD}

The results for the decision to cope in NCD households versus comparison households are presented in Table 4. Each row represents a separate regression model. For economic coping, the large positive and significant coefficients in the first column mean that an NCD death is more likely to lead to a decline in basic expenditures. The overall model in column 1 shows that a household with an NCD death is much more likely to decrease expenditure (coefficient 2.195, s.e. 0.115). The only other economic coping strategy with a significant positive association with NCD death is reporting a decline in social safety net transfers (coefficient 2.162, s.e. 0.639 ).

\section{[Insert Table 4 here]}

Declines in social safety net transfers also sees differences by death characteristics where households with deaths to older individuals and female deaths are more likely to experience a decline (old age coefficients 2.520 , s.e. 0.633 ; female coefficient 2.704 , s.e. 0.650 ). The other four coping strategies in the economic category: taking loans, spending savings or selling assets have significant inverse associations with having any adult NCD death (coefficients [s.e.]: -0.556 [0.164], -0.944 [0.369], -1.701 [0.136], -1.080 [0.187].

For demographic coping, an NCD death had a negative association with someone moving out of the household that does not appear to differ much by the characteristics of the deceased (coefficient -1.335 , s.e. 0.212 ). Having someone move into the household is positively associated with an NCD death in many of the models and is largest for a prime age death (coefficient 1.034, s.e. 0.440 ). For the behavioural coping strategies, no models show an association with having a member marry early. Having an old age death or a female death, though, was inversely associated with having someone leave education (old age coefficient -0.555 , s.e 0.242 ; female coefficient - 
0.579 , s.e. 0.294$)$. Neither demographic nor behavioural coping strategies are associated with the initial economic status of the household.

Overall, when compared to households with no NCD death, the coping strategies of reducing basic expenditure and having reduced transfers from social safety net programs appear to be the most likely coping strategies that a household uses. Deaths to prime age individuals lead to a higher likelihood of having someone move into the household and behavioural coping in terms of leaving education is only an issue when there is an old age or female death.

\subsection{Difference-in-Difference Results for Household Composition}

The results for the DiD analysis in table 5 shows the ordinary least squares regression model results for changes to the four outcomes of household composition. Model 1 shows the results for the unadjusted regression with any NCD death and model 2 shows the results for the model with any NCD death including all of the household controls. Models 3 and 4 also include the exogenous household level controls and include dummy variables for the prime age status of the deceased and for the sex of the deceased.

The results of both the unadjusted model 1 and the adjusted model 2 show that the total change in the household size is -0.7 , which is significant at $p<0.10$, indicating that households are able to attract new members. A DiD estimate of -1 would mean perfect non-replacement and a DiD estimate of zero would mean perfect replacement. The estimate of -0.7 means that for every 100 households with deaths, 30 of them are able to attract new members. For prime age status and sex of the deceased, households with a prime age death and with a female death are able to replace members. The prime age deaths give a DiD estimate of -0.45 , and female deaths give a DiD estimate of -0.62 . Households with deaths to older individuals and males do not show a significant effect. 
[Insert Table 5 here]

The DiD results were further explored for male, female, and childhood replacement with three tables in Appendix A. Compared to males, the results show more replacement for females with a significant coefficient of -0.49 for males and -0.31 for females (Table A.1 and A.2). An interesting difference between the replacement of males and females is seen by comparing the differences for prime age and non-prime age deaths for the two outcomes. While the prime age status of the deceased has no bearing on the change in total males, households with prime age deaths are more likely to replace total adult females. With a coefficient of -0.12 (Table A.2), 88 out of 100 households are replacing prime age females while only 51 out of 100 households are replacing prime age males (DiD estimate -0.49 , Table A.1). Model 4 for each of these outcomes is consistent with the sex of the deceased, showing significant declines in males and females that match the sex of the deceased.

The change in children in the household given an adult death shows significant increases after a death (Table A.3). For every 100 households, 10 of them will add a child after death. This result also changes depending on the age or sex of the deceased member. Households with a death to an older member see a significant increase in the number of children, with a positive and significant coefficient of 0.13 and households with deaths to females see a positive and significant coefficient of 0.23 . This means that for every 100 households with an old age death or every 100 households with a female death, approximately 13 and 23 of them will add one child after the death.

In summary, the DiD analysis shows that households moderately replace human capital after an NCD death, and a prime age death is more likely to lead to human capital replacement. This is mainly driven by the replacement of adult females after a prime age death. There is also evidence 
that households balance dependency ratios and labour arrangements by adding children after old age and female deaths.

\section{Discussion}

The findings show that after an adult NCD death, households cope through the reduction in expenditure on basic items such as food and utilities. This is seen even when a comparison is made to a counterfactual group of households with no death. A reduction in basic household expenditure is troubling since reductions in basic expenditure have been reported to be harmful to the diet of children as well as their cognitive development ${ }^{21,36}$. Reductions to household expenditure may also have intra-household impacts and disproportionately affect lower status members, such as females. A reduction in basic expenditure is also positively associated with longer periods of severe illness and with deaths to male members. These results indicate that a death to a male member may have greater repercussions for the household while a longer period of severe morbidity may pose higher costs as a result of medical expenditures and reduced human capital.

Deaths to prime age household members has also been reported in the literature to have important economic consequences ${ }^{23,37}$. A prime age death is associated with three out of the ten coping strategies in all of the three categories. The positive relationship of a prime age death with coping due to selling assets is troublesome if those assets may be used for income generation ${ }^{38}$. In this study, we cannot observe which specific assets were sold; however, the selling of assets means that formal financial coping mechanisms, such as insurance and safety net programs are not adequate to offset the costs of the adverse health.

Another finding is the changes in how households cope after an NCD death depending on a priori economic condition. Being in the bottom $40 \%$ of a self-rated economic condition led to a positive relationship with taking out a high interest institutional loan. This finding is consistent with 
previous work showing that the poor are less likely to have informal networks such as friends or family to smooth the effects of health events ${ }^{39}$. Poor households incurring high interest loans may be caught in a poverty trap that worsens their economic situation. There are also indications that households that are poor have a much more limited set of financial coping options available. This is seen with the somewhat counterintuitive results that poor households are less likely to spend savings and sell assets, which has been seen in other studies in low income countries ${ }^{18,40}$. The limited option for the poor further emphasizes the need for affordable coping options for these households.

The analysis of household composition finds that there is moderate replacement of household members after an adult death. The overall finding was that $30 \%$ of households replace human capital and households are more likely to replace female human capital after a prime age death than they were male human capital. This may be because of re-marriage and the lack of available prime age men. A similarly designed study in Tanzania found an estimate of $20 \%$ demographic replacement after deaths ${ }^{23}$. The results were also consistent with the broader analysis of coping strategies finding that households with an NCD death were more likely to report having someone move into the household. Further, the likelihood of reporting having someone move in increased for prime age deaths and deaths with longer periods of severe morbidity. This indicates that households with prime age deaths and with longer severe illness are able to take measures to offset foreseeable impacts ${ }^{23}$.

There are several limitations of this work that are worth highlighting. The setting in Matlab may be less generalizable to other low income settings because of its history of health research and health service provision. Our primary independent variable of NCD death may also miss the presence of sick individual in our comparison group, which would bias our estimates downwards if households in the comparison group realize financial hardship due to NCD morbidity. Another limitation may be the bias from the self-reported nature of reporting coping strategies. This could 
lead to recall bias that overestimates the economic impact. However, given that our DiD analysis, which uses an objective outcome, finds similar effects, it is encouraging that there is consistency with the subjective reporting. A final limitation is that causal conclusions are limited if the NCD death is not a true shock, which is likely to be the case due the chronic nature of NCDs.

The understanding of the coping strategies that households use after a health shock provides important insights for policy. The large percentage of households reporting reductions in expenditure on basic items may indicate that households are not fully insured against the effects of health shocks from adult NCD deaths. This has been found to be the case in Indonesia where households do not smooth consumption and experience more severe effects from chronic illness ${ }^{41}$. In rural Bangladesh, micro-lending has been shown as an effective mechanism for reducing the impact of adverse health ${ }^{24}$. Further incorporations of community based health insurance or building micro-insurance packages into the current micro-lending options could be directions for developing these mechanisms, although recent attempts to do this show that low demand for micro-insurance may undermine this option ${ }^{42}$. Other policies that may be explored are cash transfers and life insurance.

\section{Conclusion}

This study examines how households cope in terms of financial, demographic and behavioural strategies after an adult NCD death in rural Bangladesh. Households with adult NCD deaths are most likely to use economic strategies such as reducing basic expenditure, but they also deplete assets and savings and take on high interest loans. Adverse NCD health for males also appears to be most harmful as surviving female family members are less able to replace the human capital loss from males in this rural setting.

Unpacking the link between illness and poverty through the coping mechanisms that has implications for designing policies for financial protection for households in low- and middle- 
income countries, and our analysis provides guidance for tailoring policies to address negative coping behaviours. For example, access to affordable credit and insurance markets are needed to prevent further sliding of households into long-term poverty due to harmful coping related to reducing expenditure on basic items and accessing high interest loans. Deaths to prime age household members are also shown to cause significant economic consequences to households, consistent with previous literature, and this paper explicitly explores this link for NCDs in low income settings. In reality, households use a mix of different coping strategies to maximize their specific objectives given the prices of the strategies and their own constraints. Future work should attempt to understand how these coping decisions impact on long-term poverty.

\section{Ethical Approval}

This research has been approved by the Institutional Review Board of the Johns Hopkins Bloomberg School of Public Health and the International Centre for Diarrhoeal Disease Research, Bangladesh (icddr,b).

\section{References}

1. Jha P, Nugent RA, Verguet S, Bloom D, Hum R. Chronic Disease. In: Lomborg B, ed. Global Problems, Smart Solutions: Costs and Benefits. Cambridge: Cambridge University Press; 2013:137-169.

2. Ahsan Karar Z, Alam N, Kim Streatfield P. Epidemiological transition in rural Bangladesh, 1986-2006. Glob Health Action. 2009;2.

3. Abu-Zaineh M, Arfa C, Ventelou B, Ben Romdhane H, Moatti J-P. Fairness in Healthcare Finance and Delivery: What about Tunisia? 2014; 4:433-442. Available at, 29.

4. Mirelman AJ, Rose $\mathrm{S}$, Khan JA, et al. The relationship between non-communicable disease occurrence and poverty-evidence from demographic surveillance in Matlab, Bangladesh. Health Policy Plan. 2016.

5. Razzaque A, Nahar L, Abu Haider Mohammad Golam M, Karar Zunaid A, Mohammad Shafiqul I, Yunus M. Sociodemographic differentials of selected noncommunicable diseases risk factors among adults in Matlab, Bangladesh: findings from a WHO STEPS survey. Asia Pac J Public Health. 2011;23(2):183-191.

6. Dercon S. Income Risk, Coping Strategies, and Safety Nets. The World Bank Research Observer. 2002;17(2):141-166.

7. Mclntyre $D$, Thiede $M$, Dahlgren $G$, Whitehead $M$. What are the economic consequences for households of illness and of paying for health care in low- and middle-income country contexts? Soc Sci Med. 2006;62(4):858-865. 
8. Nguyen KT, Hai Khuat OT, Ma S, Pham DC, Hong Khuat GT, Ruger JP. Coping with health care expenses among poor households: Evidence from a rural commune in Vietnam. Social Science \& Medicine. 2012;74(5):724-733.

9. Ruger JP. An Alternative Framework for Analyzing Financial Protection in Health. PLoS Med. 2012;9(8):e1001294.

10. Begum S, Sen B. Maternal health, child well-being and chronic poverty: does women's agency matter? The Bangladesh Development Studies. 2009;32(4):26.

11. Ferreira PC, Pessoa S, Dos Santos MR. The impact of AIDS on income and human capital. Economic Inquiry. 2011;49(4):1104-1116.

12. WHO. WHO guide to identifying the economic consequences of disease and injury. Geneva: World Health Organization;2009.

13. Attanayake N, Fox-Rushby J, Mills A. Household costs of 'malaria' morbidity: a study in Matale district, Sri Lanka. Trop Med Int Health. 2000;5(9):595-606.

14. Mahal A, Karan A, Fan VY, Engelgau M. The economic burden of cancers on Indian households. PLOS ONE. 2013;8(8):e71853.

15. Mills A. The economic consequences of malaria for households: a case-study in Nepal. Health Policy. 1994;29(3):209-227.

16. Steinberg M, Johnson S, Schierhout G, Ndegwa D. Hitting Home: How households cope with the impact of the HIV/AIDS epidemic. Henry J. Kaiser Family Foundation;2002.

17. Rahman PMM, Matsui N, Ikemoto Y. Dynamics of Poverty in Rural Bangladesh. Japan: Springer; 2013.

18. Santos I, Sharif I, Rahman HZ, Zaman H. How Do the Poor Cope with Shocks in Bangladesh? Evidence from Survey Data. In. Policy Research Working Paper. Washington, DC: The World Bank; 2011:24.

19. Dhanaraj S. Health Shocks and Coping Strategies. In. WIDER Working Paper. Helsinki, Finland: UNU-WIDER; 2014:28.

20. Lundberg M, Over M, Mujinja P. Sources of Financial Assistance for Households Suffering an Adult Death in Kagera,Tanzania. South African Journal of Economics. 2000;68(5):948-984.

21. Powell-Jackson T, Hoque ME. Economic consequences of maternal illness in rural Bangladesh. Health Econ. 2011.

22. Kruk ME, Goldmann E, Galea S. Borrowing and selling to pay for health care in low- and middle-income countries. Health Aff (Millwood). 2009;28(4):1056-1066.

23. Yamano T, Jayne TS. Measuring the Impacts of Working-Age Adult Mortality on SmallScale Farm Households in Kenya. World Development. 2004;32(1):91-119.

24. Islam A, Maitra P. Health shocks and consumption smoothing in rural households: Does microcredit have a role to play? Journal of Development Economics. 2012(97):232-243.

25. Khandker S, Samad H. Dynamic Effects of Microcredit in Bangladesh. In. Policy Research Working Paper: The World Bank; 2014:50.

26. Acharya A, Vellakkal S, Taylor F, et al. The Impact of Health Insurance Schemes for the Informal Sector in Low and Middle-Income Countries. In. Policy Research Working Paper: The World Bank; 2013:1-46.

27. Roodman D, Morduch J. The Impact of Microcredit on the Poor in Bangladesh: Revisiting the Evidence. The Journal of Development Studies. 2014;50(4):583-604.

28. Grimm M. Mortality Shocks and Survivors' Consumption Growth*. Oxford Bulletin of Economics and Statistics. 2010;72(2):146-171.

29. Singh S, Samara R. Early Marriage Among Women in Developing Countries. International Family Planning Perspectives. 1996;22:148-157. 
30. Kinsey B, Burger K, Gunning JW. Coping with Drought in Zimbabwe: Survey Evidence on Responses of Rural Households to Risk. World Development. 1998;26(1):89-110.

31. Rothman KJ, Greenland S, Lash TL. Modern Epidemiology. 3rd ed: Lippincott Williams and Wilkins; 2012.

32. Razzaque A, Streatfield PK. Matlab DSS, Bangladesh. In: Population and health in developing countries Ottawa: International Development Research Centre; 2002:287295.

33. WorldBank. Open Data Repositor. 2014; data.worldbank.org. Accessed May 24, 2014, 2014.

34. Greene WH. Econometric Analysis. 7th Edition ed. London: Pearson Education; 2012.

35. Bonfrer I, Gustafsson-Wright E. Health shocks, coping strategies and foregone healthcare among agricultural households in Kenya. Glob Public Health. 2016:1-22.

36. Grantham-McGregor S, Cheung YB, Cueto S, et al. Developmental potential in the first 5 years for children in developing countries. Lancet. 2007;369(9555):60-70.

37. Beegle K, De Weerdt J, Dercon S. Adult Mortality and Consumption Growth in the Age of HIV/AIDS. Economic Development and Cultural Change. 2008;56:299-326.

38. Beegle K, Weerdt JD, Dercon S. Adult Mortality and Consumption Growth in the Age of HIV/AIDS. Economic Development and Cultural Change. 2008;56(2):299-326.

39. Dupas P. Health Behavior in Developing Countries. Annual Review of Economics. 2011;3:425-449.

40. Heltberg R, Lund N. Shocks, Coping, and Outcomes for Pakistan's Poor: Health Risks Predominate. The Journal of Development Studies. 2009;45(6):889-910.

41. Gertler P, Gruber J. Insuring Consumption against IIIness. American Economic Review. 2002;92(1):51-70.

42. Bannerjee A, Duflo E, Hornbeck R. Building Health Insurance and Microfinance in India: There Cannot be Adverse Selection if there is no Demand. American Economic Review: Papers and Proceedings. 2014;104(5):291-297. 


\section{Tables}

Table 1. Descriptive Information for Study Population at Baseline

\begin{tabular}{|c|c|c|c|}
\hline \multirow[b]{2}{*}{ Variable } & NCD death & Comparison & $\begin{array}{l}\text { Test for diff. } \\
\text { (NCD vs. } \\
\text { Comparison) }\end{array}$ \\
\hline & $\begin{array}{c}\text { Mean } \\
\text { (SD)/Proportion } \\
\end{array}$ & $\begin{array}{c}\text { Mean } \\
\text { (SD)/Proportion } \\
\end{array}$ & $\begin{array}{c}\text { (p-value or } \\
\left.X^{2}\right) \\
\end{array}$ \\
\hline \multicolumn{4}{|c|}{ 1. Household-level Control Variables } \\
\hline Household size & $6.18(2.70)$ & $6.23(3.02)$ & 0.68 \\
\hline Head Age & $61.76(13.92)$ & $62.62(13.72)$ & 0.14 \\
\hline Head Female & $0.23(0.01)$ & $0.23(0.01)$ & 0.82 \\
\hline Head Education (year) & $2.84(3.69)$ & $2.87(3.59)$ & 0.79 \\
\hline Muslim & 0.85 & 0.87 & 0.34 \\
\hline Poor & 0.44 & 0.43 & 0.43 \\
\hline \multicolumn{4}{|c|}{ 2. Individual-level Variables (Deceased Individual and Matched Individual) } \\
\hline Age & $67.71(12.72)$ & $67.33(12.33)$ & 0.48 \\
\hline Prime Age (\%15-59) & 0.21 & 0.21 & 0.94 \\
\hline Female & 0.45 & 0.45 & NA \\
\hline Head/Spouse of Head & 0.66 & 0.73 & 0.00 \\
\hline Length Severe Illness (year) & $0.36(1.18)$ & NA & NA \\
\hline $\mathbf{N}$ & 856 & 1695 & \\
\hline \multicolumn{4}{|c|}{$\begin{array}{l}\text { Note: NA (not applicable) applies to the test for difference for sex because of exact matching or because } \\
\text { the variable doesn't apply to the group. All values are estimated in the baseline year prior to death, } \\
\text { calendar year 2009. Poor is defined as being in wealth quintiles } 1 \text { or 2, based on PCA of assets in } 2005 . \\
\text { There is ambiguity in the literature about whether accounting for matched variables in a matched cohort } \\
\text { analysis is needed. We use a t-test statistic for continuous variables and assuming independence between } \\
\text { the groups. A paired t-test may also be used in matched cohort study, and we find similar result when } \\
\text { using a paired or unpaired test but only report the unpaired results (Cummings, McKnight, \& Weiss, 2003; } \\
\text { Sjolander \& Greenland, 2013). A chi squared test for independence is used for categorical variables } \\
\text { (Faraway, 2006). }\end{array}$} \\
\hline
\end{tabular}


Table 2. Percentage of households reporting multiple coping activities

\begin{tabular}{cccc}
\hline & NCD death (N=856) & & Comparison (N=1695) \\
\cline { 2 - 2 } Number of Strategies & \% Using & \% Using \\
\hline \hline $\mathbf{0}$ & $42.3 \%$ & $41.6 \%$ \\
$\mathbf{1}$ & $42.0 \%$ & $38.0 \%$ \\
$\mathbf{2}$ & $12.4 \%$ & $14.9 \%$ \\
$\mathbf{3}$ & $2.9 \%$ & $4.7 \%$ \\
$\geq \mathbf{4}$ & $0.3 \%$ & $0.8 \%$ \\
Number of Categories & & \\
\hline \hline $\mathbf{0}$ & $42.3 \%$ & $41.6 \%$ \\
$\mathbf{1}$ & $51.5 \%$ & $48.7 \%$ \\
$\mathbf{2}$ & $5.4 \%$ & $8.0 \%$ \\
$\mathbf{3}$ & $0.8 \%$ & $1.8 \%$ \\
\hline
\end{tabular}

Note: The number of strategies is the total number out of a maximum possible of ten strategies. There are three categories of coping, which include Economic, Demographic and Behavioural coping strategies. Economic coping includes: reducing basic expenditure, taking out a high interest loan from a formal or informal source, selling assets, spending savings or having a decline in social safety net transfers.

Demographic coping includes: having someone move out or movie in to the household. Behavioural coping includes: having someone marry early and having someone leave education early. 
Table 3. Logistic Regression on Coping Strategy Use for Households with NCD Deaths

\begin{tabular}{|c|c|c|c|c|c|c|c|c|c|c|}
\hline & \multicolumn{6}{|c|}{ Economic } & \multicolumn{2}{|c|}{ Demographic } & \multicolumn{2}{|c|}{ Behavior } \\
\hline & $\begin{array}{l}\text { Basic } \\
\text { Expenditure }\end{array}$ & $\begin{array}{l}\text { Institutional } \\
\text { Loan }\end{array}$ & $\begin{array}{l}\text { Independent } \\
\text { Loan }\end{array}$ & Spend Savings & Sell Assets & $\begin{array}{l}\text { Decrease Soc. } \\
\text { Safety }\end{array}$ & Move Out & Move In & Marry Early & $\begin{array}{l}\text { Leave } \\
\text { Education }\end{array}$ \\
\hline (Intercept) & $\begin{array}{c}-0.307(0.501) \\
\end{array}$ & $-2.479(0.892)^{* * * *}$ & 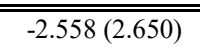 & $=-2.302(0.850)^{* * * *}$ & $-3.022(1.113)^{* * *}$ & 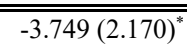 & $-4.774(1.527)^{* * *}$ & $-3.911(1.300)^{* * *}$ & $-5.126(1.255)^{* * *}$ & $-1.948(0.958)^{* * *}$ \\
\hline Prime Age & $0.119(0.196)$ & $-0.542(0.463)$ & $0.527(0.910)$ & $-0.047(0.373)$ & $1.004(0.417)^{* *}$ & $-1.332(1.239)$ & $0.886(0.521)^{*}$ & $0.420(0.521)$ & $1.243(0.540)^{* *}$ & $0.830(0.417)^{* *}$ \\
\hline Head & $-0.190(0.212)$ & $-0.105(0.489)$ & $0.805(1.045)$ & $0.124(0.392)$ & $-0.621(0.451)$ & $-0.310(1.120)$ & $0.343(0.625)$ & $0.394(0.432)$ & $-0.151(0.651)$ & $0.213(0.523)$ \\
\hline Female & $-0.272(0.161)^{*}$ & $0.272(0.309)$ & $-0.558(0.680)$ & $-0.068(0.300)$ & $0.029(0.382)$ & $1.537(0.900)^{*}$ & $-0.436(0.492)$ & $-0.789(0.494)$ & $1.387(0.633)^{* *}$ & $-0.315(0.396)$ \\
\hline Long Severe & $0.359(0.143)^{* *}$ & $0.320(0.285)$ & $1.635(0.845)^{*}$ & $0.183(0.251)$ & $0.533(0.352)$ & $-0.314(0.544)$ & $0.272(0.402)$ & $0.633(0.438)$ & $-0.082(0.574)$ & $0.591(0.348)^{*}$ \\
\hline Poor & $0.201(0.151)$ & $0.808(0.321)^{* *}$ & $0.568(0.676)$ & $-0.467(0.267)^{*}$ & $-0.678(0.409)^{*}$ & $0.638(0.568)$ & $0.497(0.440)$ & $-0.680(0.515)$ & $-0.208(0.644)$ & $0.298(0.379)$ \\
\hline $\begin{array}{l}\text { Log } \\
\text { Likelihood }\end{array}$ & -570.786 & -195.794 & -44.176 & -236.353 & -143.543 & -60.462 & -114.578 & -104.178 & -62.478 & -147.667 \\
\hline Deviance & 1141.571 & 391.588 & 88.351 & 472.706 & 287.086 & 120.923 & 229.156 & 208.356 & 124.956 & 295.333 \\
\hline Num. obs. & 845 & 845 & 845 & 845 & 845 & 845 & 845 & 845 & 845 & 845 \\
\hline
\end{tabular}

Note: $\quad p<0.01, \quad p<0.05, \quad p<0.1$. Poor is defined as being in quintiles 1 or 2 of self-rated economic condition in 2009. All models here control for household-level information. Prime age refers to being in the age group 15-59 in 2010. Long Severe refers to the natural log of the length of severe illness. Standard errors are clustered at the village level. The 845 observations is due to 9 missing individuals resulting from using control variables from previous years. 
Table 4. Logistic Regression Models on Coping Strategy Use for Entire Study Population

\begin{tabular}{|c|c|c|c|c|c|c|c|c|c|c|}
\hline \multirow{2}{*}{ Model } & \multicolumn{6}{|c|}{ Economic } & \multicolumn{2}{|c|}{ Demographic } & \multicolumn{2}{|c|}{ Behavior } \\
\hline & $\begin{array}{l}\text { Basic } \\
\text { Expenditure }\end{array}$ & $\begin{array}{l}\text { Institutional } \\
\text { Loan }\end{array}$ & $\begin{array}{l}\text { Independent } \\
\text { Loan }\end{array}$ & Spend Savings & Sell Assets & $\begin{array}{l}\text { Decrease Soc. } \\
\text { Safety Transfers }\end{array}$ & Move Out & Move In & Marry Early & Leave Education \\
\hline NCD Death & 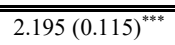 & 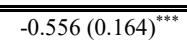 & $\begin{array}{l}-0.944(0.369)^{* *} \\
\end{array}$ & 年-1.701 (0.136) & 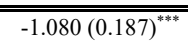 & $\begin{array}{l}2.162(0.639)^{* * * *} \\
\end{array}$ & -1.335(0.212) & $\bar{~} 0.557(0.281)^{* *}$ & $0.161(0.339)$ & $\begin{array}{c}0.269(0.196) \\
\end{array}$ \\
\hline PA NCD Death & $2.345(0.179)^{* * *}$ & $-1.123(0.363)^{* * *}$ & $-0.212(0.479)$ & $-1.716(0.286)^{* * *}$ & $-0.428(0.307)$ & $0.523(1.286)$ & $-0.735(0.330)^{* *}$ & $1.034(0.440)^{* * *}$ & $0.827(0.489)^{*}$ & $0.315(0.283)$ \\
\hline Non-PA NCD Death & $2.155(0.122)^{* * * *}$ & $-0.407(0.174)^{* *}$ & $-1.435(0.527)^{* * *}$ & $-1.697(0.151)^{* * * *}$ & $-1.319(0.227)^{* * *}$ & $2.520(0.633)^{* * *}$ & $-1.601(0.266)^{* * *}$ & $0.415(0.312)$ & $-0.145(0.415)$ & $-0.555(0.242)^{* *}$ \\
\hline Head NCD Death & $2.136(0.129)^{* * *}$ & $-0.552(0.198)^{* * *}$ & $-0.754(0.449)^{*}$ & $-1.713(0.164)^{* * * *}$ & $-1.324(0.245)^{* * *}$ & $1.740(0.730)^{* *}$ & $-1.067(0.240)^{* * *}$ & $0.585(0.330)^{*}$ & $0.185(0.400)$ & $-0.052(0.232)$ \\
\hline Non-Head NCD Death & $2.321(0.162)^{* * *}$ & $-0.562(0.243)^{* *}$ & $-1.246(0.601)^{* *}$ & $-1.675(0.227)^{* * * *}$ & $-0.654(0.280)^{* *}$ & $2.524(0.743)^{* * *}$ & $-1.947(0.433)^{* * *}$ & $0.503(0.405)$ & $0.118(0.564)$ & $-0.648(0.331)^{*}$ \\
\hline Female NCD Death & $2.103(0.140)^{* * *}$ & $-0.443(0.216)^{* *}$ & $-1.334(0.603)^{* *}$ & $-1.721(0.199)^{* * * *}$ & $-0.971(0.262)^{* * *}$ & $2.704(0.650)^{* * *}$ & $-1.840(0.371)^{* * *}$ & $0.187(0.396)$ & $0.589(0.431)$ & $-0.579(0.294)^{* *}$ \\
\hline Male NCD Death & $2.267(0.133)^{* * * *}$ & $-0.663(0.216)^{* * *}$ & $-0.674(0.440)$ & $-1.685(0.176)^{* * * *}$ & $-1.168(0.251)^{* * *}$ & $0.907(0.915)$ & $-1.016(0.248)^{* * *}$ & $0.805(0.330)^{* *}$ & $-0.318(0.493)$ & $-0.047(0.232)$ \\
\hline Long Morbidity Death & $2.373(0.135)^{* * *}$ & $-0.384(0.207)^{*}$ & $-0.435(0.412)$ & $-1.614(0.183)^{* * *}$ & $-0.827(0.233)^{* * *}$ & $2.033(0.701)^{* * *}$ & $-1.265(0.286)^{* * *}$ & $0.820(0.325)^{* *}$ & $0.208(0.440)$ & $-0.044(0.241)$ \\
\hline Short Morbidity Death & $2.027(0.134)^{* * * *}$ & $-0.737(0.225)^{* * *}$ & $-1.821(0.727)^{* *}$ & $-1.788(0.189)^{* * * *}$ & $-1.381(0.283)^{* * *}$ & $2.272(0.688)^{* * * *}$ & $-1.404(0.293)^{* * * *}$ & $0.233(0.388)$ & $0.116(0.430)$ & $-0.525(0.277)^{*}$ \\
\hline
\end{tabular}

Note: ${ }^{* * *} p<0.01, \quad{ }^{* *} p<0.05,{ }^{*} p<0.1$. All models (each row) includes controls for all household and individual level variables. Standard errors are clustered at the village level. Poor is defined as being in quintiles 1 or 2 of self-rated economic condition in 2009. 
Table 5. Difference in Difference Estimates for Total Household Size

\begin{tabular}{|c|c|c|c|c|}
\hline & \multicolumn{4}{|c|}{ Total Household Size } \\
\hline & Model 1 & Model 2 & Model 3 & Model 4 \\
\hline (Intercept) & $6.227(0.074)^{* * *}$ & $6.664(0.207)^{* * *}$ & $6.736(0.208)^{* * *}$ & $6.610(0.208)^{* * *}$ \\
\hline Death & $-0.702(0.157)^{*}$ & $-0.702(0.152)^{*}$ & & \\
\hline PA Death & & & $-0.449(0.253)^{* *}$ & \\
\hline Non-PA Death & & & $-0.770(0.166)$ & \\
\hline Female Death & & & & $-0.615(0.193)^{* *}$ \\
\hline Male Death & & & & $-0.773(0.190)$ \\
\hline $\mathbf{R}^{2}$ & 0.048 & 0.1 & 0.101 & 0.101 \\
\hline Adjusted $\mathbf{R}^{2}$ & 0.047 & 0.098 & 0.099 & 0.1 \\
\hline Num. obs. & 5020 & 5020 & 5020 & 5020 \\
\hline
\end{tabular}

